\title{
Changes in children's diet and physical activity as perceived by their mothers: Impact of a health promotion intervention for mothers in a sub-urban area of Nepal
}

\section{Oli $N^{1}$, Vaidya $A^{2}$, Eiben $\mathbf{G}^{3}$, Krettek $A^{4}$}

${ }^{1}$ Natalia Oli, Lecturer; ${ }^{2}$ Abhinav Vaidya, Professor, Department of Community Medicine, Kathmandu Medical College, Kathmandu, Nepal; ${ }^{3}$ Gabriele Eiben, Assistant Professor, Department of Biomedicine and Public Health, School of Health and Education, University of Skövde, Skövde, Sweden; ${ }^{4}$ Alexandra Krettek, Professor, Department of Internal Medicine and Clinical Nutrition, Institute of Medicine, Sahlgrenska Academy at University of Gothenburg, Gothenburg, Sweden; Department of Biomedicine and Public Health, School of Health and Education, University of Skövde, Skövde, Sweden; Department of Community Medicine, Faculty of Health Sciences, UiT The Arctic University of Norway, Tromsø, Norway.

\begin{abstract}
Background: Unhealthy diet and physical inactivity contribute to the growing burden of cardiovascular diseases in Nepal. Lifestyle is formed in childhood and in the Nepalese context influenced mainly by mothers, it is to date unknown how influential mothers are.

Objectives: To assess changes in children's diet and physical activity as perceived by their mothers after a health promotion intervention.

Methodology: The Heart-Health Associated Research, Dissemination and Intervention in the Community is a community trial conducted in the Jhaukhel-Duwakot Health Demographic Surveillance site, in Bhaktapur district of Nepal. We conducted a health promotion intervention on diet and physical activity targeted at mothers with children aged one to nine years old in August-November 2016. Duwakot was randomized as the intervention site and Jhaukhel as the control. We conducted a follow-up study after three months to determine the outcome of the intervention. Nine trained enumerators conducted door-to-door visits to all households with eligible mothers. We calculated mean, frequency and percent changes for children's behavior.

Results: As responded by mothers, children in Duwakot consumed more healthy snacks after the intervention compared to Jhaukhel. Children in Duwakot increased consumption of water and milk. Children's consumption of packet juices and soft drinks was decreased by $30 \%$ and $4 \%$ respectively. There was $21 \%$ increment in the duration of outdoor playing among the children at Duwakot during follow-up.

Conclusion: The Heart-Health Associated Research, Dissemination and Intervention in the Community that focused on mothers showed indirect positive impact on their young children's diet and physical activity behavior. In future, the longterm effects of such intervention should be assessed.
\end{abstract}

Key words: Behavior; Children; Diet; Health promotion; Physical activity.

DOI: https://doi.org/10.3126/jkmc.v7i4.23298

\section{INTRODUCTION}

Tepal as a low income country is facing rising prevalence of non-communicable diseases $(\mathrm{NCDs})^{1}$. Among the NCDs, cardiovascular diseases

Address for correspondence

Dr. Natalia Oli

Lecturer, Department of Community Medicine

Kathmandu Medical College

Kathmandu, Nepal

E-mail: olinatalia1@gmail.com
(CVDs) are the most common causes of hospitalization². Unhealthy diet and low physical activity are wellknown behavioral risk factors which contribute to non-communicable diseases especially in low income countries $^{3}$. Thus, a rapid nutritional transition in Nepal (shifts from traditional diet to the universal high-energy dense diet), along with increasing physical inactivity at work, leisure and travel time are responsible for rise in overweight and obesity among adults, children, and adolescents ${ }^{4,5}$. 
In relation to CVD, we usually consider the adult population but rarely think about children as individuals at risk ${ }^{6}$. Although morbidity and mortality from NCDs mainly occur in adulthood, exposure to risk factors begins in early life? ${ }^{7}$. In fact, both healthy and unhealthy habits related to diet and physical activity form in early childhood and continue into adulthood ${ }^{8}$. Thus, diabetes and hypertension are more common among overweight children compared to children with normal weight ${ }^{9}$. In fact, the family food environment is crucial for establishing children's behavior (e.g., dietary habits) ${ }^{10}$. Parents, especially mothers in Nepal, are responsible for creating a family environment and lifestyle that will affect children throughout life.

We have earlier shown high prevalence of unhealthy diet and physical inactivity in the general population, including mothers with young children ${ }^{11,12}$, in the Jhaukhel-Duwakot Health Demographic Surveillance Site (JD-HDSS) ${ }^{13}$. Experiences from high income countries show that community-based health promotion programs may delay death from CVD by several decades, thus avoiding premature deaths among middle-aged people. Moreover, interventions early in life have the beneficial and long-term potential to counteract and decrease the CVD epidemic ${ }^{8}$.

We therefore developed the Heart-Health Associated Research, Dissemination and Intervention in the Community (HARDIC) project which includes a health promotion intervention that targeted mothers with young children. This paper evaluated the impact of the health promotion program on children's diet and physical activity, as perceived by their mothers.

\section{METHODOLOGY}

\section{Study setting and population}

The HARDIC project was conducted in JD-HDSS, which consists of two villages-Jhaukhel and Duwakot-in the mid-hills of Bhaktapur district, 13 kilometers outside Kathmandu, the capital of Nepal ${ }^{13}$. The baseline study was conducted in both Duwakot and Jhaukhel during September-November 2014 to explore knowledge, attitude and practice regarding diet and physical activity of mothers with children one to seven years old. We also explored children's diet and physical activity behavior as perceived by their mothers ${ }^{14}$.

To improve cardiovascular health among children through their mothers, we used our findings from the baseline study and developed a health promotion program that focused on diet and physical activity. The intervention was implemented from August to November 2016 in two rounds of educational classes. We randomly allocated Duwakot as the intervention site and Jhaukhel as the control area. To minimize contamination bias, we selected five wards in Duwakot that did not border the control area. The control area included all nine wards of Jhaukhel ${ }^{15}$.

\section{HARDIC intervention}

The HARDIC intervention applied the peer education approach. We selected peer mothers from the baseline list of eligible mothers in the intervention area and trained them regarding diet and physical activity. Later, each trained peer mother conducted four educational classes. Round 1 in their households to teach other eligible mothers ('fellow mothers') living in their neighborhood, in the ratio of 1:10. Round 2 consisted of one class, one month apart from Round 1. We provided peer mothers with health education materials such as flip charts and health education manuals. The fellow mothers also received the manuals. Field supervisors supervised field work and conducted process evaluation on a daily basis. Details of the intervention are published elsewhere ${ }^{15}$.

\section{Follow-up data collection}

We conducted the follow-up study three months after the intervention among all mothers with children aged one to nine years in Duwakot (five intervention wards) and all wards in Jhaukhel (control area). One of the objectives of the follow-up was to assess the impact of the health promotion intervention on children's diet and physical activity behaviour as perceived by their mothers. The study excluded mothers with hearing or mental disorders or those with mentally ill children or children whose health condition required a special diet and physical regime. Mothers who lived in the community for only a few months due to seasonal work (e.g., in brick kilns) were excluded.

Nine trained enumerators, with assistance from one main supervisor and three field supervisors, conducted door-to-door visits to all the households with eligible mothers during January-February 2017. If there were more than one eligible mother in the household, the enumerators used a lottery method to select one interviewee. If a selected mother was absent during the household visit, the enumerators contacted her by phone and met with her at her convenience. In families with more than one child aged one to nine, the oldest child was included in the study. 


\section{Tools}

For the follow-up, we used the same questionnaire that we had used during the baseline study ${ }^{14}$. It was used to obtain information about mothers' perception of their children's diet-related behavior and physical activity, the type of food children consumed as snacks and during main meals, favorite food items and drinks, how often children consumed soft drinks or pre-packaged juices, how they spent free time, and how much time their children spentwatching screen, etc.

We tailored the questionnaire to the local context and discussed it within our research group. The questionnaire was translated from English into Nepali language and then back-translated into English. We pretested the questionnaire and made necessary changes. Additionally, we checked the questionnaire for internal consistency (Cronbach's alpha $=0.7$ ).

\section{Data analysis}

Data was analyzed using the Statistical Package for the Social Sciences (SPSS), version 23.0 (IBM, Armonk, New York, USA). Descriptive statistics was used to calculate mean with standard deviation (SD), frequency and percent changes for particular behavior of the children.

\section{Ethical consideration}

The Nepal Health Research Council provided ethical approval of this study (No. 150/2014). To each respondent, the objectives of the study were explained and informed consent was obtained. Confidentiality and anonymity were ensured during the study. Additionally, mothers from the control area received governmentpublished pamphlets on NCDs and behavioral risk factors during the follow-up survey.

\section{RESULTS}

\section{Socio-demographic Profile}

Altogether 1,276 mothers (626 in Duwakot and 650 in Jhaukhel) participated in the follow-up study in JDHDSS. The mean (SD) age of the mothers at follow-up was 30.1 (5.1) years and for children was 5(2.3) years. Forty three percent of the children were girls. Most of the children were from Newar families (35\%), followed by Chhetri (30\%) and Hill Ethnic casts (18.5\%). Almost half of mothers (49.8\%) completed grade 5-10, and most of them were housewives (69\%). Most of the children lived in nuclear families (78\%). More than half $(53.5 \%)$ of the families had average monthly household income 10,000-20,000 Nepalese rupees.

\section{Dietary changes among the children}

After analyzing mothers' responses to questions related to their children's dietary behavior, we found that children in the intervention area had improved their diet compared to children in the control area. To illustrate this, we calculated percent changes from baseline to follow-up for mothers' responses regarding their children's behavior in Duwakot and Jhaukhel. Figure 1 shows changes in the children's choice of snacks.

Healthy items were chosen more often by children in Duwakot after the intervention compared to Jhaukhel. Nonetheless, many children in Duwakot had increased consumption of unhealthy snacks as well, but this increment was much less compared to Jhaukhel.

Similarly, information regarding change in children's favorite drinks was obtained from mothers. It was evident that many children in the intervention area changed their preferences towards healthier drinks such as water and milk (Figure 2). Indeed, children in Duwakot decreased consumption of packet juices (-30\% changes) and soft drinks (-4\% changes) compared to an increased consumption of these items in Jhaukhel (3\% and $11 \%$ changes, respectively).

\section{Changes among children's physical activity}

Mothers also reported how their children spent their free time during the previous week. Figure 3 shows that the percent changes for children playing with friends at home was slightly higher in the intervention compared to the control area ( $23 \%$ and $21 \%$ changes, respectively). Interestingly, the number of children playing outside home increased in Duwakot (12\% changes) and decreased in Jhaukhel (-6\% changes) after the intervention. Also, despite that children more often used television, computer or mobile in both villages during follow up, the percent changes was less in Duwakot (5\% changes) after the intervention compared to Jhaukhel ( $9 \%$ changes).

Similarly, we assessed the amount of time the children played outside as well as their screen time (using mobile, computer, and watching television) during weekdays and weekends as per their mother's perception during baseline and follow-up. Children in the intervention and control areas had improved their physical activity as the number of them playing outside home during weekdays and weekends increased. However, changes were more pronounced in the intervention area compared to control. Furthermore, although children increased their screen time during weekdays in both 
Duwakot and Jhaukhel, the percent changes were less in Duwakot (11\% changes) compared to Jhaukhel $(22 \%$ changes). Additionally, children in Duwakot decreased their screen time during weekends (-1\% changes) compared to an increment of two percent change in Jhaukhel (Figure 4).

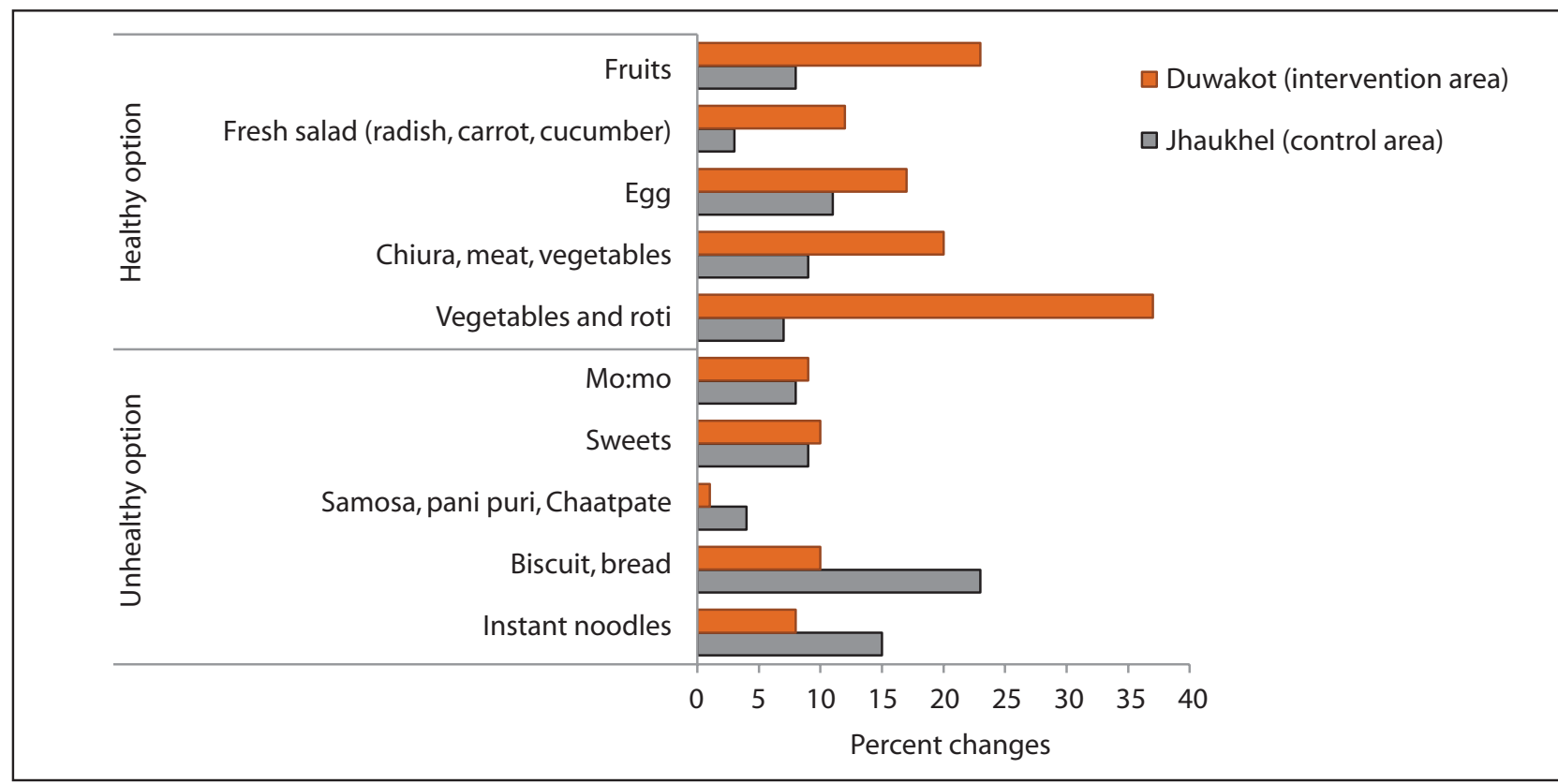

Figure 1: Percent change in children's snack preferences as perceived by their mothers in Duwakot and Jhaukhel from baseline to follow-up.

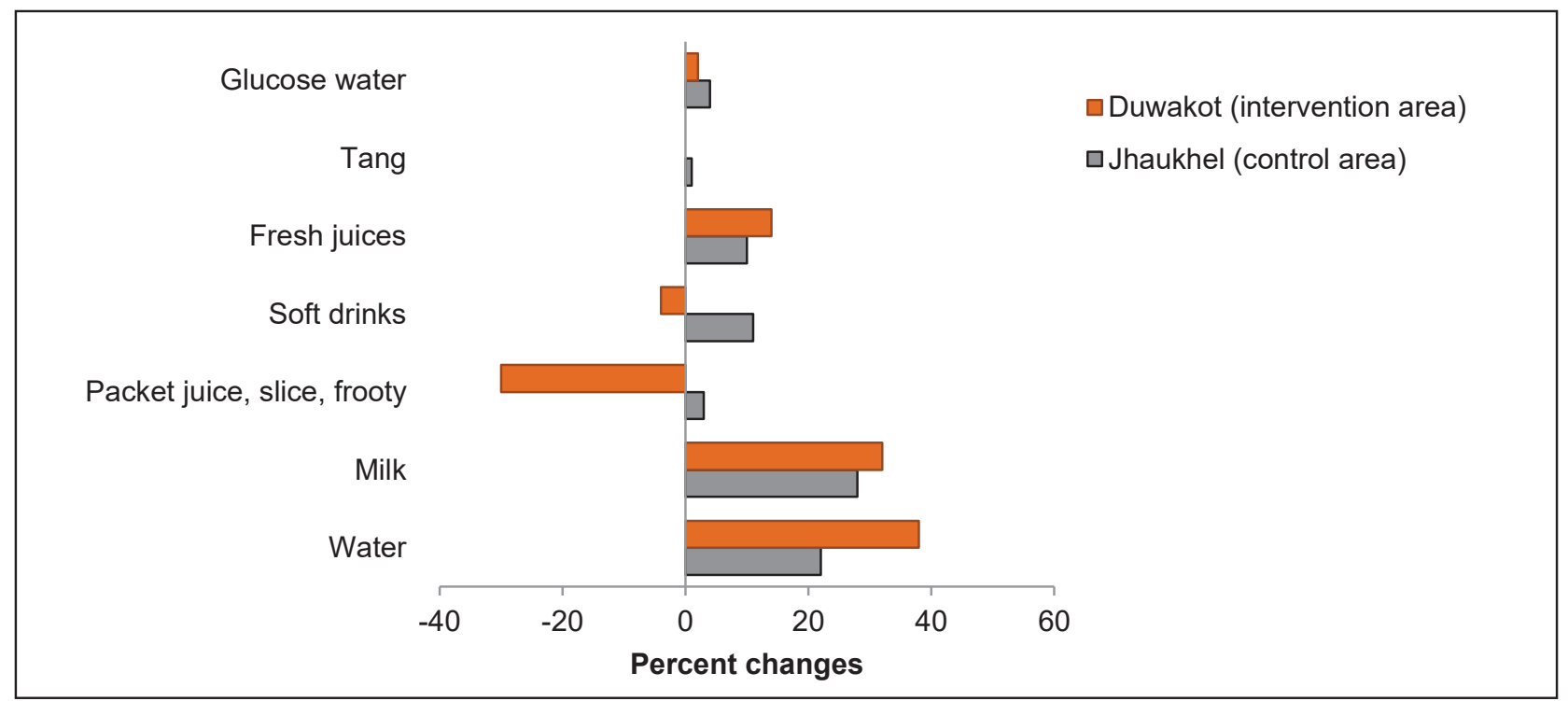

Figure 2: Percent change in children's favorite drinks as perceived by their mothers in Duwakot and Jhaukhel from baseline to follow-up. 


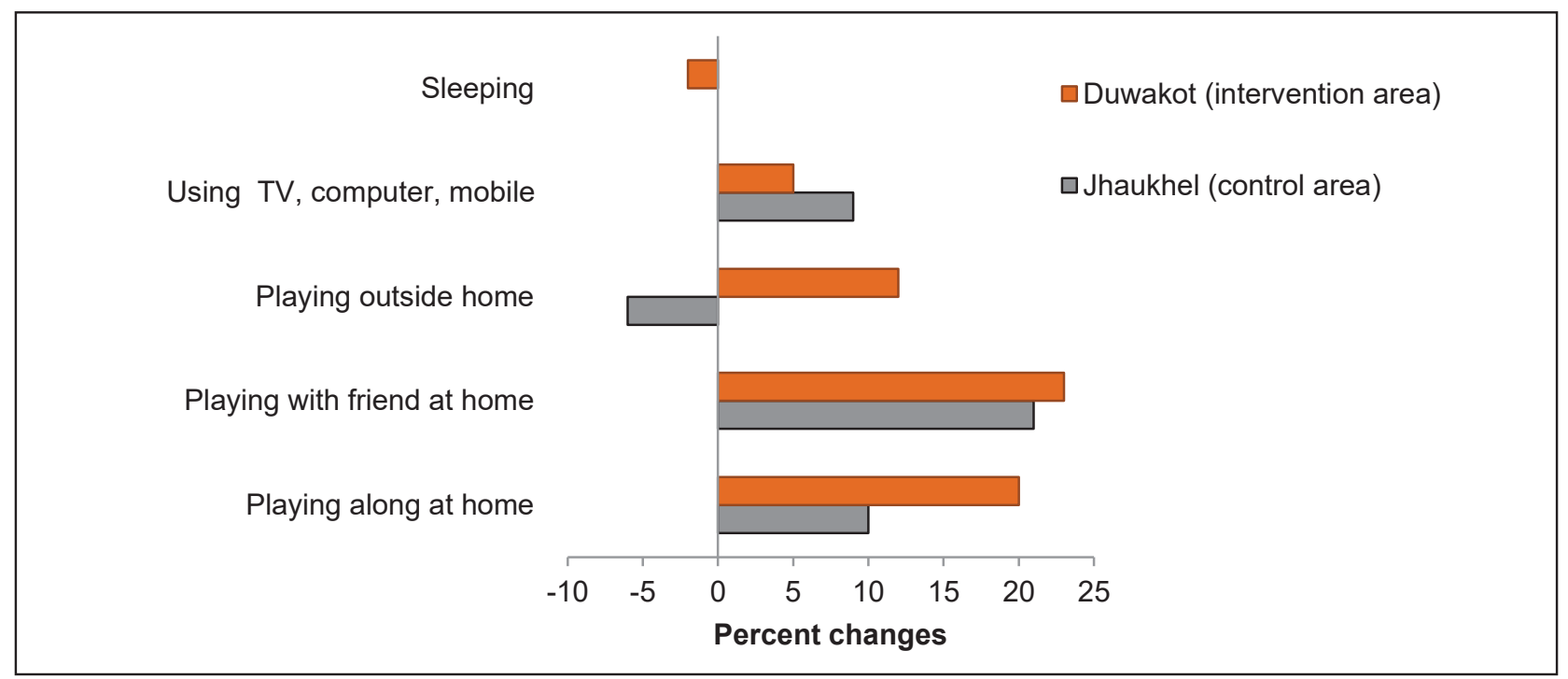

Figure 3: Percent change in children's physical activity during their free time as perceived by their mothers in Duwakot and Jhaukhel from baseline to follow-up.

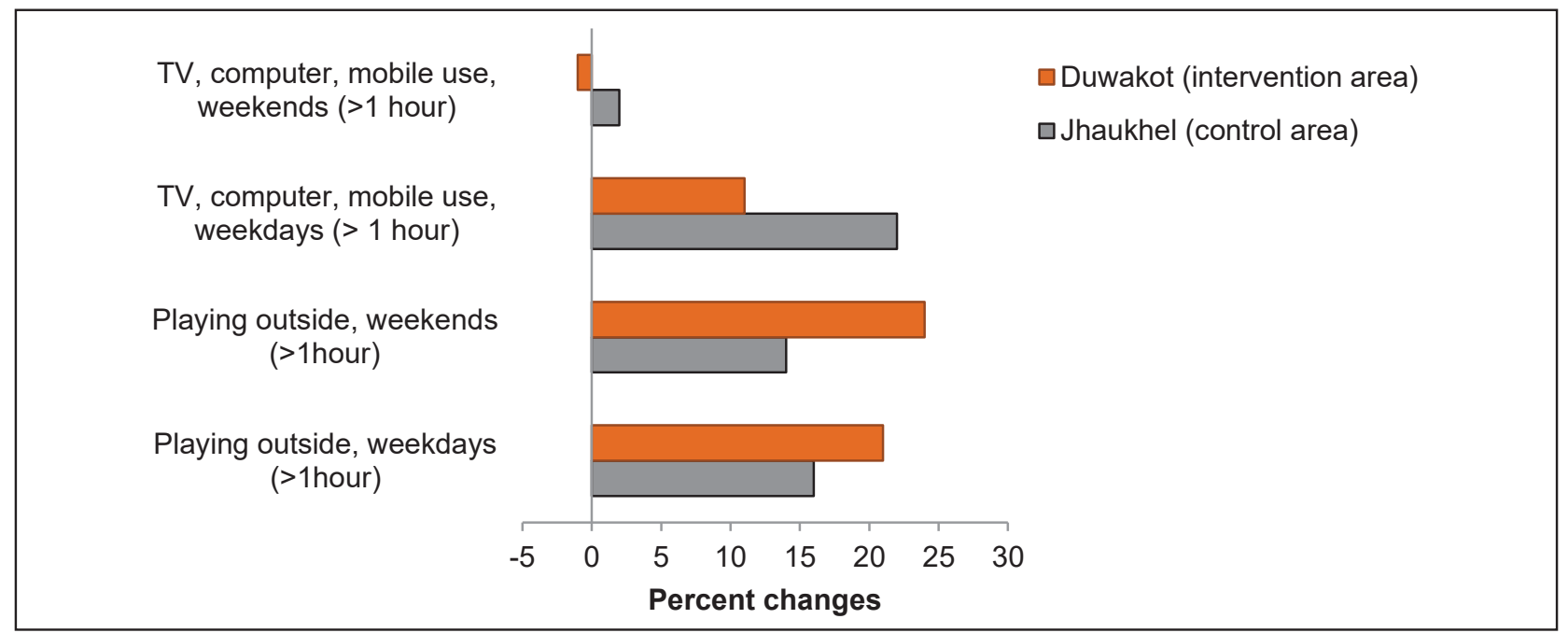

Figure 4: Percent change in children's screen time and playing outside during weekdays and weekends as perceived by their mothers in Duwakot and Jhaukhel from baseline to follow-up.

\section{DISCUSSION}

The HARDIC project, developed by us, is unique because it is the first attempt in Nepal to address diet and physical activity among mothers with young children, and to indirectly improve children's diet and physical activity behavior. We assessed changes in dietary and physical activity, as perceived by mothers with children aged one to nine years, before and after a health promotion intervention. The HARDIC project demonstrates positive effects towards healthy lifestyle changes among children in the intervention area compared to the control area and suggests that the developed educational material is useful for future health promotive strategies in the community.
In fact, the family food environment is crucial for establishing children's dietary and physical activity behavior, especially for children of young $\mathrm{age}^{10}$. Knowledge about nutrition and parents' feeding practices, especially mothers' in Nepal context, are important key elements of their children's food environment. Hence, we have chosen mothers with young children as the target group for a health promotion intervention in our study ${ }^{16}$. Previous studies have confirmed that mother's knowledge positively affects their children's physical activity and eating habits ${ }^{17,18}$. Therefore, we expected that the HARDIC intervention would improve mothers' positive attitude towards their children's diet and physical activity, and 
in turn,this could indirectly lead to positive changes in their children's behavior.

We assessed children's behavior changes for several variables such as items consumed for snacks, favorite drinks, how children spent their free time, time children spent playing outside home and their screen time on weekdays and weekends. As expected, we found that many children began to choose healthier snacks in the intervention area compared to control. Similar changes were observed in relation to children's favorite drinks as well. These positive dietary changes concur with other studies ${ }^{16,19}$. Similarly, more children started to play outside home and spent longer time outside during weekdays as well as on weekends in the intervention area. In contrast, similar changes were less remarkable in the control area. One of the reasons for positive changes in the control area could be that we did not follow same children before and after the intervention, hence variation is possible in the community. Additionally, we found that children in the intervention area reduced their screen time during weekends. This was supported by other studies ${ }^{20}$. However, some interventions did not demonstrate reduction in children's screen time ${ }^{21}$.

Despite the positive changes in the intervention area, we observed an increased trend of consumption of unhealthy food in both the intervention and control areas. A similar trend was found for screen time during weekdays. Thus, a general continuous community-rise in consumption of fast food and beverages along with screen time of children is an established phenomenon in low and middle income countries such as Nepal'. It is fueled by junk food advertisements targeting children, availability of fast food outlets with attractive design,

\section{REFERENCES}

1. Rayner M, Mendis S. An Introduction to PopulationLevel Prevention of Non-Communicable Diseases. New York: Oxford University Press; 2017.

2. Bhandari GP, Dhimal M, Neupane S. Prevalence of non-communicable diseases in Nepal, Hospital based study. Nepal Health Research Council, Ramshat Path, Kathmandu Nepal. 2010: 1-80.[DOI]

3. Kohl HW, 3rd, Craig CL, Lambert EV, Inoue $\mathrm{S}$, Alkandari JR, Leetongin G, et al. The pandemic of physical inactivity: global action for public health. Lancet. 2012; 380(9838): 294-305.[PubMed]

4. Subedi YP, Marais D, Newlands D. Where is Nepal in the nutrition transition? Asia Pac J Clin Nutr[Internet]. 2017 [cited 2016 January 3]; 26(2): 358-67.[DOI] easy access to the internet and lack of playgrounds. Therefore, to bring changes in children's behavior, interventions should target all possible driving forces for unhealthy diet and low physical activity in the community. Also involving children along with their parents in physical activities would be more effective to counteract the trend of unhealthy diet and insufficient physical activity.

Our study had some limitations. One of them is that we did not directly assess dietary and physical activity behavior of the children, but rather based our results on their mothers' perceptions of such behavior. This may influence the results, as the mothers' perception may differ from their child's actual dietary and physical activity. Also the evaluation was subjective, based on the mothers' responses, which can also be biased. We did not measure duration of screen time or physical activity due to practical difficulties in assessing them. Also we did not follow the same mothers before and after the intervention, but rather measured the impact of the health promotion intervention on children's behavior at the community level. Hence, natural changes of the population due to internal migration may influence the results.

\section{CONCLUSION}

The HARDIC health promotion intervention, focusing on mothers with young children and being based on peer education, was effective inimproving children's diet and physical activity behavior. However, long term assessment of the effectiveness of the intervention is required. Furthermore, health promotion efforts that address diet and physical activity should be expanded beyond mothers and applied to other community members, e.g., fathers and pupils in school settings.

5. Ranasinghe $C D$, Ranasinghe $P$, Jayawardena $R$, Misra A. Physical activity patterns among South-Asian adults: a systematic review. International Journal of Behavioral Nutrition and Physical Activity [Internet]. 2013 [cited 2014 May 20]; 10(1): 116.[DOI]

6. Tunstall-Pedoe H. Preventing Chronic Diseases. A Vital Investment: WHO Global Report. Geneva: World Health Organization, [Internet] 2005 [cited 2014 January 15]. pp 200. Available from: https://www. who.int/chp/chronic_disease_report/en/[DOI]

7. World Health Organization. Global action plan for the prevention and control ofnoncommunicable diseases 2013-2020. Geneva: World Health Organization; [Internet] 2013 [cited 2014 May13. Available from: https://www.who.int/nmh/events/ ncd_action_plan/en/[DOI] 
8. Darnton-Hill I NC, James W. A life course approach to diet, nutrition and the prevention of chronic diseases. Public health nutrition [Internet]. 2004 [cited 2014 May13]; 7(1A): 101-21. Available from: https://www. ncbi.nlm.nih.gov/pubmed/14972056[Full text]

9. Raj M, Sundaram KR, Paul M, Deepa AS, Kumar RK. Obesity in Indian children: time trends and relationship with hypertension. The National medical journal of India [Internet]. 2007 [cited 2015 April 5]; 20(6): 288-93. Available from: https://www.ncbi.nlm. nih.gov/pubmed/?term=Obesity+in+Indian+childre $\mathrm{n} \% 3 \mathrm{~A}+$ time+trends+and+relationship+with+hyper tension.[PubMed]

10. Hendrie GA, Coveney J, Cox DN. Defining the complexity of childhood obesity and related behaviours within the family environment using structural equation modelling. Public health nutrition [Internet]. 2012 [cited 2015 September 11]; 15(01): 48-57. [PubMed]

11. Vaidya A, Aryal UR, Krettek A. Cardiovascular health knowledge, attitude and practice/behaviour in an urbanising community of Nepal: a population-based cross-sectional study from Jhaukhel-Duwakot Health Demographic Surveillance Site. BMJ Open [Internet]. 2013 [cited 2015 September 15]; 3(10): e002976. [DOI]

12. Oli N, Vaidya A, Subedi M, Eiben G, Krettek A. Diet and physical activity for children's health: a qualitative study of Nepalese mothers' perceptions. BMJ Open [Internet]. 2015 [cited 2016 October 6]; 5(9): e008197. [DOI]

13. Aryal UR, Vaidya A, Shakya-Vaidya S, Petzold M, Krettek A. Establishing a health demographic surveillance site in Bhaktapur district, Nepal: initial experiences and findings. BMC research notes [Internet]. 2012 [cited 2015 January 3]; 5(1): 489.[DOI]

14. Oli N, Vaidya A, Pahkala K, Eiben G, Krettek A. Knowledge, attitude and practice on diet and physical activity among mothers with young children in the Jhaukhel-Duwakot Health Demographic Surveillance Site, Nepal. PloS one [Internet]. 2018 [cited 2018 September 24]; 13(7): e0200329.[DOI]
15. Vaidya A, Oli N, Eiben G, Krettek A. The Hearthealth Associated Research, Dissemination and Intervention in the Community (HARDIC) Trial for Nepalese Mothers regarding Diet and Physical Activity: A Process Evaluation. Kathmandu Univ Med J. 2017; 58(2): 107-16.[Full text]

16. Hendrie G, Sohonpal G, Lange K, Golley R. Change in the family food environment is associated with positive dietary change in children. Int J Behav Nutr Phys Act [Internet]. 2013 Jan 7 [cited 2014 April 4];10:4. [DOI]

17. Yabancı N, Kısaç, Karaku S. The Effects of Mother's Nutritional Knowledge on Attitudes and Behaviors of Children about Nutrition. Procedia - Social and Behavioral Sciences[Internet]. 2014 [cited 2015 May 13]; 116: 4477-81. Available from: http://www. sciepub.com/reference/240362[DOI]

18. Pearson N, Timperio A, Salmon J, Crawford D, Biddle SJ. Family influences on children's physical activity and fruit and vegetable consumption. Int J Behav Nutr Phys Act [Internet]. 2009 Jun 16 [cited 2015 April 16];6:34. doi: 10.1186/1479-5868-6-34.[PubMed]

19. Simell O, Niinikoski $H$, Rönnemaa $T$, Lapinleimu $H$, Routi T, Langström H, et al. Special Turku Coronary Risk Factor Intervention Project for Babies (STRIP). The American journal of clinical nutrition. 2000; 72(5 Suppl): 1316s-31s.[DOI]

20. Schmidt ME, Haines J, O'Brien A, McDonald J, Price $S$, Sherry $B$, et al. Systematic review of effective strategies for reducing screen time among young children. Obesity (Silver Spring, Md). 2012; 20(7): 1338-54.[PubMed]

21. Wahi G, Parkin PC, Beyene J, Uleryk EM, Birken CS. Effectiveness of interventions aimed at reducing screen time in children: a systematic review and meta-analysis of randomized controlled trials. Archives of pediatrics \& adolescent medicine [Internet]. 2011 [cited 2016 May 23]; 165(11): 979-86. doi: 10.1001/archpediatrics.2011.122. Epub 2011 Jul 4.[PubMed] 